Additional services for Cardiology in the Young:

Email alerts: $\underline{\text { Click here }}$

Subscriptions: $\underline{\text { Click here }}$

Commercial reprints: $\underline{\text { Click here }}$

Terms of use : $\underline{\text { Click here }}$

\title{
The anatomy of interatrial communications - what does the interventionist need to know?
}

José Diogo Ferreira Martins and Robert H. Anderson

Cardiology in the Young / Volume 10 / Issue 05 / September 2000, pp 464 - 473

DOI: 10.1017/S1047951100008155, Published online: 19 August 2008

Link to this article: http://journals.cambridge.org/abstract_S1047951100008155

How to cite this article:

José Diogo Ferreira Martins and Robert H. Anderson (2000). The anatomy of interatrial communications - what does the interventionist need to know?. Cardiology in the Young,10, pp 464-473 doi:10.1017/S1047951100008155

Request Permissions : $\underline{\text { Click here }}$ 


\title{
The anatomy of interatrial communications - what does the interventionist need to know?
}

\author{
José Diogo Ferreira Martins, ${ }^{1}$ Robert H. Anderson ${ }^{2}$ \\ ${ }^{1}$ Department of Paediatric Cardiology, Hospital de Santa Cruz, Lisbon, Portugal; ${ }^{2}$ Cardiac Unit, Institute of Child Health, \\ University College, London, United Kingdom
}

\begin{abstract}
Increasingly, the interventional cardiologist is seeking to close interatrial communications by inserting devices by means of catheterisation. So as to optimise these procedures, it is advantageous to have a firm grasp of the anatomy of the normal atrial septal structures, this then providing the basis to understand the morphology of the holes which can exist between the chambers, not all of which are true septal defects. A true septal structure can be removed without exiting from the cavities of the heart. It is the flap valve of the oval fossa, along with the anterior rim of the fossa, which fulfill this criterion. The remainder of the extensive rim of the normal fossa is no more than an infolding between the walls of the right and left atriums and their venous tributaries, and has different dimensions at various points around the circumference. The so-called muscular atrioventricular "septum" is a sandwich incorporating a layer of epicardial fibro-adipose tissue. True defects of the atrial septum, therefore, exist because of deficiency, perforation, or absence of the flap valve. Most of these defects will prove suitable for interventional closure, but potential caveats include multiple defects, aneurysm of the flap valve, or adjacency of the fossa to the venous orifices. The other interatrial communications, namely the sinus venosus, coronary sinus, and "ostium primum" defects are outside the confines of the oval fossa. Recognition of this feature is the key to their diagnosis, and their differentiation from true atrial septal defects. Of these defects, only the coronary sinus defect is likely to be suitable for device closure, and then only in the very rare circumstances when it is seen in isolation.
\end{abstract}

Keywords: Atrial septum; arrial septal defect; oval fossa defecr; sinus venosus defect; coronary sinus defect; ostium primum defect

I NCREASINGLY, THE INTERVENTIONIST IS SEEKING to close holes between the atrial chambers so as to avoid opening the chest. The key to success is to determine those holes which lend themselves to non-surgical closure, as opposed to those which might produce unacceptable difficulties in closure, or those in which the margins of the defect are insufficiently discrete adequately to anchor the device inserted to attempt closure. This, selfevidently, requires knowledge of the location of defects relative to the atrial septum. This, in turn, demands an appreciation of normal septal

Correspondence to: Professor R. H. Anderson, Cardiac Unit, Institute of Child Health, 30 Guilford Street, London WCIN 1EH, UK. Tel: +44-(0)20-7905-2295; Facsimile+44-(0)20-7905-2324; E-mail: r.anderson@ih.ucl.ac.uk

Accepted for publication 6 June 2000 structure. The choice of the device to be inserted will also depend, on occasion, on the specific anatomic features of the defect to be closed. Of the morphological studies carried out with deviceclosure in mind, however, ${ }^{1-4}$ only one ${ }^{4}$ has been specifically concerned with a device currently in use. In this review, therefore, we will commence by describing the normal interatrial septal structures. We will then give an account of defects within the oval fossa, suggesting which variants might, on morphological grounds, be less than optimal for interventional closure. We will conclude with a brief review of the structure of the more complex interatrial communications, namely the sinus venosus and coronary sinus defects, and the "primum" variant of atrioventricular septal defects, showing why, for the most part, these are not suitable for interventional closure. 


\section{The structure of the normal atrial septum}

So as to facilitate our descriptions of interatrial communications, it is best if we begin by giving an account of our own understanding of septal structures. This requires a distinction to be made between those walls of the heart which directly separate adjacent chambers, as opposed to folds, or sandwiches, which can interpose between the chambers, but only at the cost of incorporating a layer of extracardiac adipose tissue. ${ }^{5}$ Excision of such a fold or sandwich would produce a communication with the extracardiac space. A wall which interposes directly between two chambers, in contrast, can be removed without exiting from the cavities of the heart. It is the latter structure which, in our opinion, constitutes a true septal structure. These distinctions are important when we consider normal cardiac anatomy.

When the normal right atrium is opened to permit inspection of its septal surface, it seems at first sight that there is an extensive area potentially interposed between the right and left atriums (Fig. 1). In this respect, it is also important to describe the cardiac structures in attitudinally appropriate orientation. ${ }^{6}$ When the heart is in the body, the mouth of the superior caval vein is directly above that of the inferior caval vein, and the apex of the triangle of Koch points upwards (Fig. 1). Thus, the superior rim of the oval fossa is that directly beneath the mouth of the superior caval vein, whilst the anterior rim separates the fossa from the triangle of Koch, with the tendon of Todaro extending through it (Fig. 1). Sectioning a different heart (Figs 2-4) shows that much of the apparently septal area, specifically the larger parts of the rim of the oval fossa, is composed of either folds or sandwiches. The true septal wall dividing the cavities of the atriums is no more than the flap valve of the oval fossa, together with its supporting muscular anterior rim adjacent to the triangle of Koch. The flap valve, a derivative of the primary atrial septum, ${ }^{7}$ forms the entirety of the floor of the oval fossa (Fig. 5). The superior margin of the fossa is a deep infolding of the atrial walls between the attachments of the superior caval vein to the right atrium and the pulmonary veins to the left atrium (Figs 4,5 ). The margin of the fossa adjacent to the inferior caval vein is rarely a discrete structure, while the wall adjacent to the orifice of the coronary sinus is a further fold. Only the antero-inferior rim itself, continuous anteriorly with the area of the atrioventricular muscular sandwich, is a true intracardiac buttress (Fig. 5). The coronary sinus runs as a discrete muscular tube within the left atrioventricular groove, with fibroadipose tissue separating its walls from the posterior wall of the left atrium. ${ }^{8}$ The commissure of the valves which, in some hearts, guard the mouths of the inferior caval vein and the coronary sinus (the Eustachian and Thebesian valves, respectively) runs from inferiorly through the anterior rim of the fossa as the tendon of Todaro (Fig. 3). This area is also called the Eustachian ridge.

\section{Defects within the oval fossa}

It is only those holes found within the margins of the oval fossa which are the true atrial septal defects. These communications are often called "secundum"

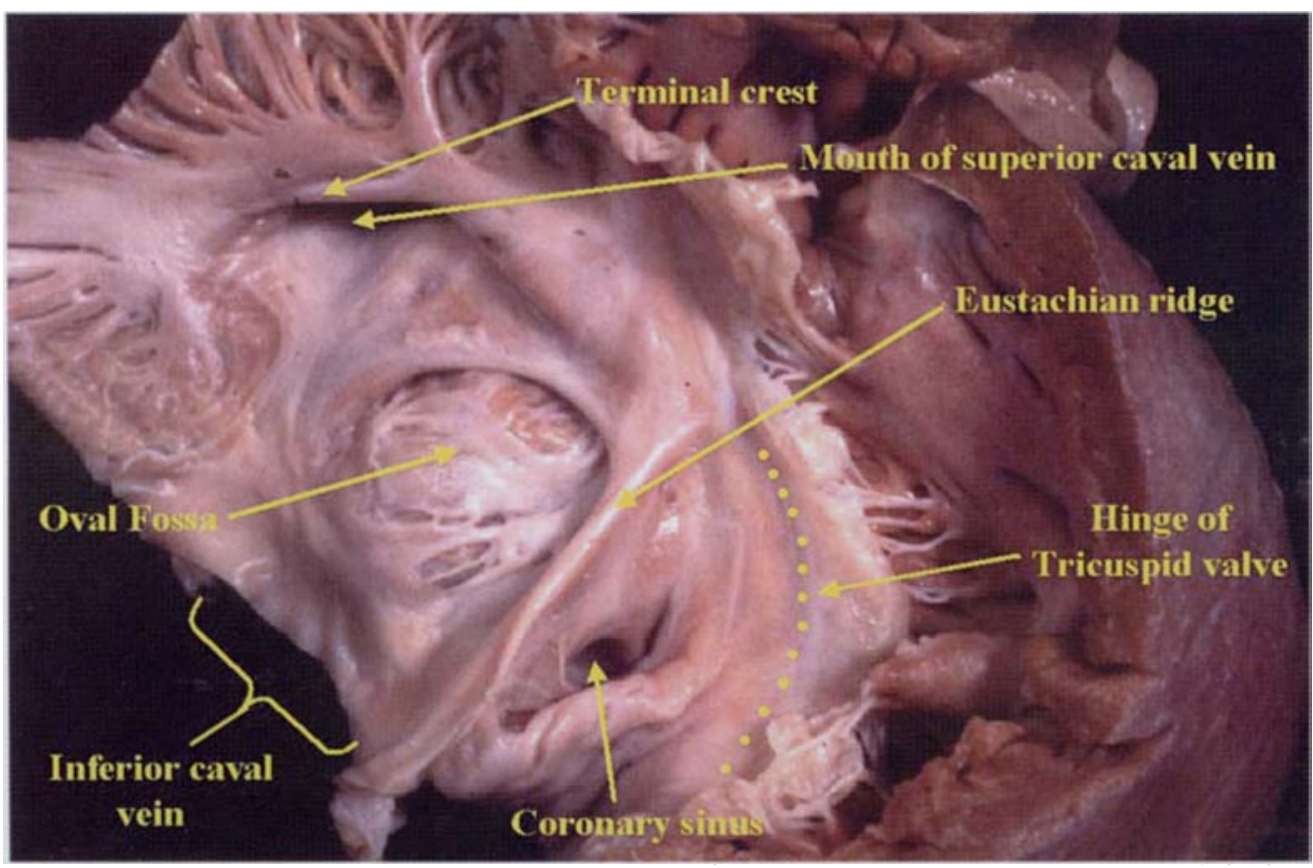

Figure 1.

The right atrium has been opened to show its septal aspect. The specimen is orientated in attitudinally correct position, with the superior caval vein directly above the inferior caval vein, and the apex of the triangle of Koch directed superiorly. Note the location and relationships of the oval fossa. 


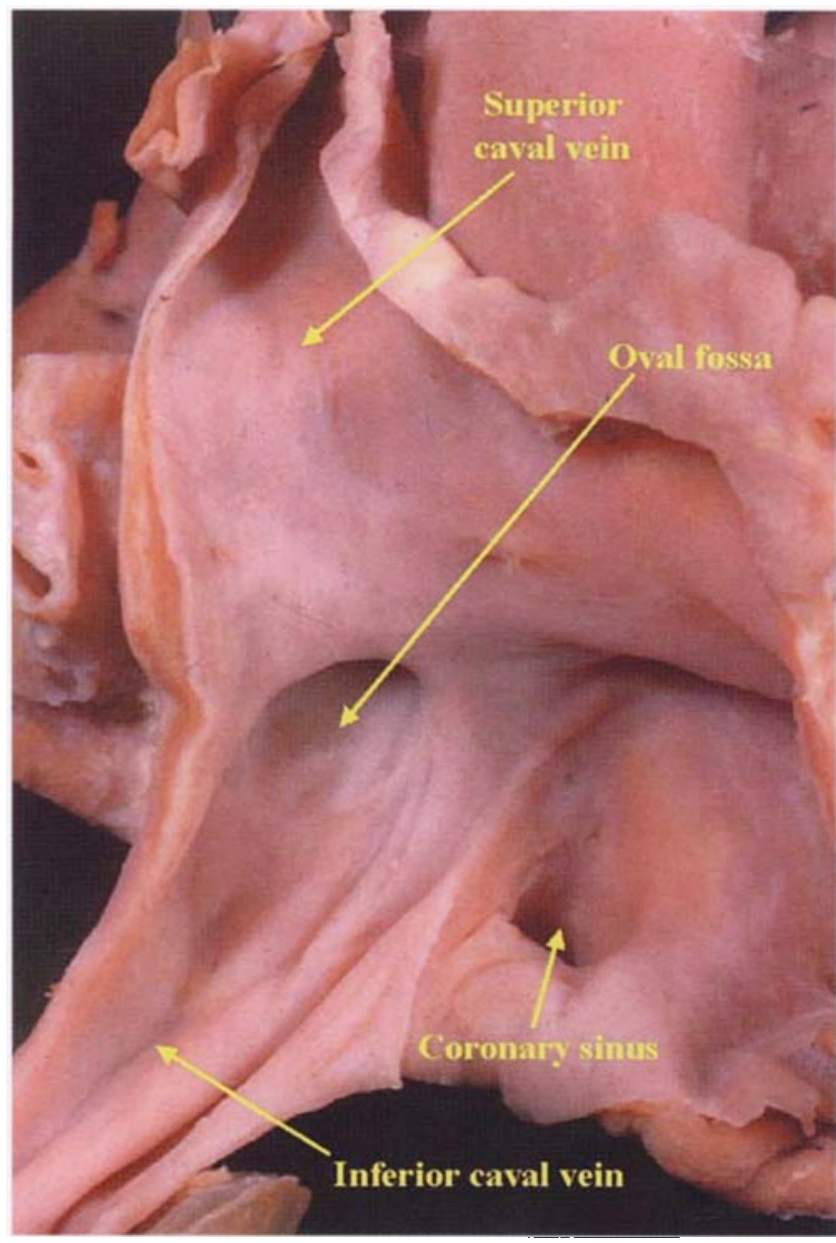

Figure 2 .

This beart bas also been opened to show the septal aspect of the right atrium (compare with Fig. 1). Note the persistent Eustachian valve. defects, but they exist because of deficiencies of the flap valve which, as mentioned above, is derived from the primary atrial septum. In one third of the normal population, however, the upper margin of the fibrous flap valve overlaps the infolded anterosuperior rim of the oval fossa without being fused to it. ${ }^{\text {Th }}$ This produces a probe-patent oval foramen. Such probe-patency does not produce the potential for interatrial shunting as long as left atrial pressure is higher than right. It is possible, nonetheless, to envisage the situation in which either pressure or volume overload of the atriums could efface the superior rim of the fossa. This would then produce an interatrial communication, but one which would disappear if the cause of overload was removed, with disappearance at the same time of the potential for atrial shunting. This seems to be the most likely mechanism of so-called spontaneous closure of interatrial communications, said to occur with some frequency during the neonatal period. ${ }^{10}$ Probepatent oval foramens can themselves produce problems in adult life, however, when they can produce problems for deep-sea divers, or be the cause of stroke or transient ischaemic attacks. In these circumstances, they are ideal candidates for interventional closure. ${ }^{11}$ It is deficiencies of the flap valve which are responsible for producing defects within the oval fossa. Such defects can take one of three morphologic variants:

- When the flap valve is of insufficient dimensions to overlap the rim (Fig. 6).

- When the flap valve is perforated or filigreed (Fig. 7).

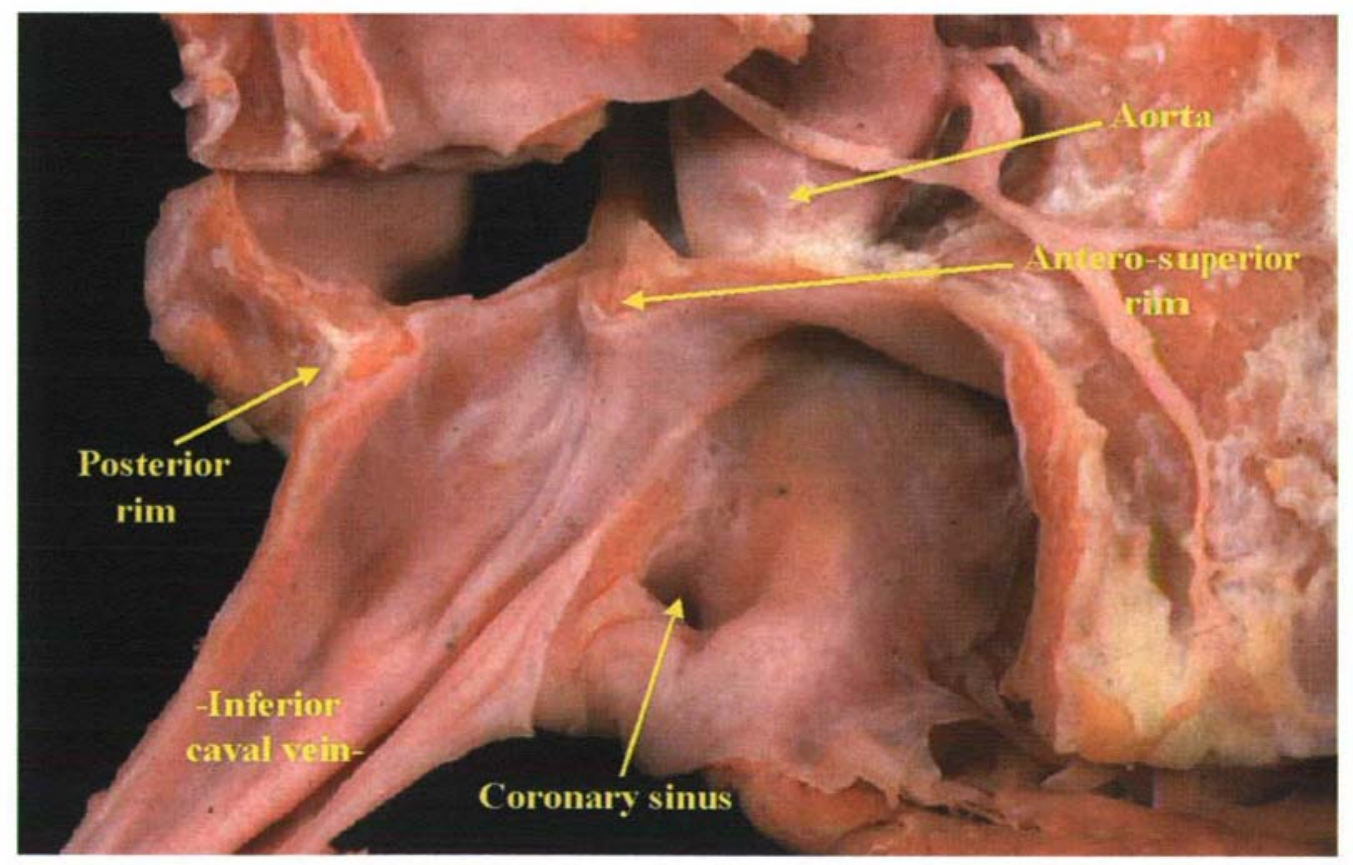

Figure 3.

The beart shown in Fig. 2 bas been sectioned across the transverse axis of the oval fossa, showing the infolding of the atrial walls antero-superiorly in relation to the aortic root (the aortic mound) and posteroinferiorly relative to the inferior caval vein. 


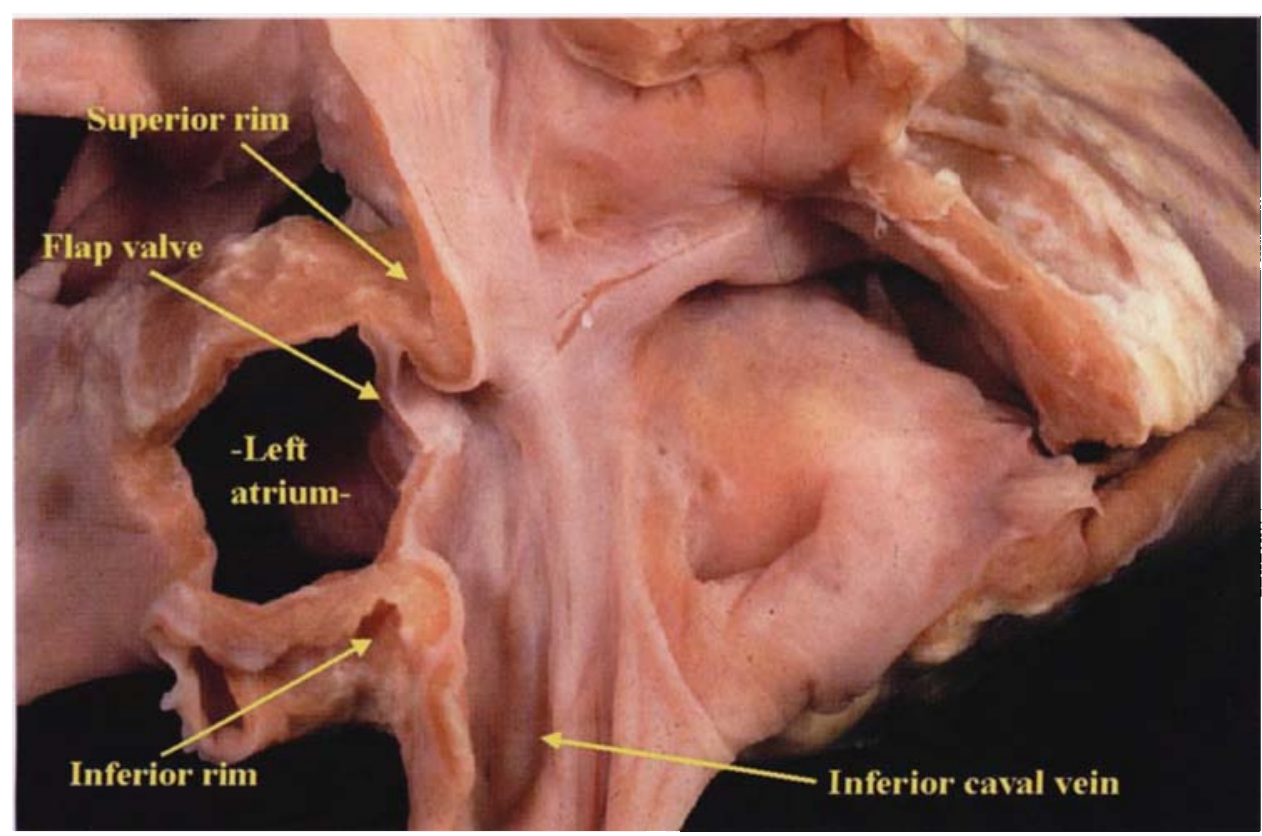

Figure 4.

The heart shown in Fig. 2 bas been reconstituted baving made the transverse section shown in Fig. 3, and sectioned along the orthogonal axis of the oval fossa. Note the deep superior infolding beneath the mouth of the superior caval vein the supposed "septum secundum".

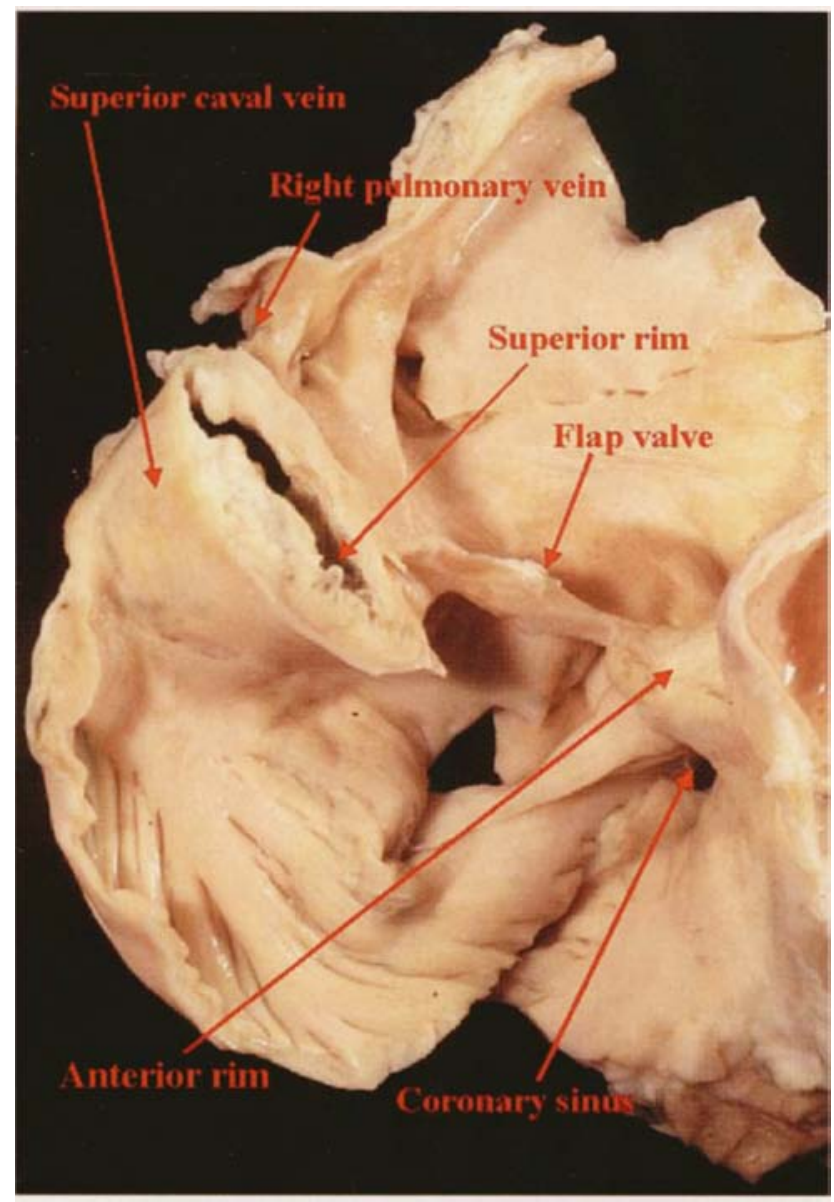

Figure 5.

This adult beart has been dissected to show the structure of the oval fossa. The thin flap valve is anchored on the firm anterior rim, here sectioned at the point where it becomes contiguous with the aortic mound. The superior rim is the deep infolding between the superior caval and right pulmonary veins.
- When the entirety of the flap valve is virtually or completely absent (Fig. 8).

When the flap valve is perforated, this selfevidently results in the presence of multiple defects within the confines of the oval fossa.

The important morphological questions that need to be answered by the interventionist concern:

- The dimensions, shape and number of the defect.

- The adequacy of the rims of the defect which will hold the device in place.

- The location of the defect relative to the surrounding atrial structures.

When measuring the dimensions of the defect, it is usual to consider its two longest orthogonal diameters. The echocardiographic planes best suited for making these measurements are described in the accompanying review. ${ }^{12}$ Usually the defect itself is ellipsoid, but can be oval when occupying the full extent of the oval fossa (compare Figs 6 and 8). The number of defects to be found when the flap valve is filigreed can vary markedly, and this can be difficult to determine echocardiographically (see Fig. 7). In these circumstances, it is probably best to take the area of the oval fossa itself as the area of the defect.

When considering the adequacy of the rims, and here again it is necessary to take echocardiographic measurements, ${ }^{12}$ it helps to understand their anatomic nature as discussed and illustrated above (see Figs 3-5). The anterior rim of the fossa is the most substantial part of the circumference, since this is a true septal structure (Fig. 5). This rim is directly continuous with the area of the muscular atrioventricular sandwich which, although incorporating a 


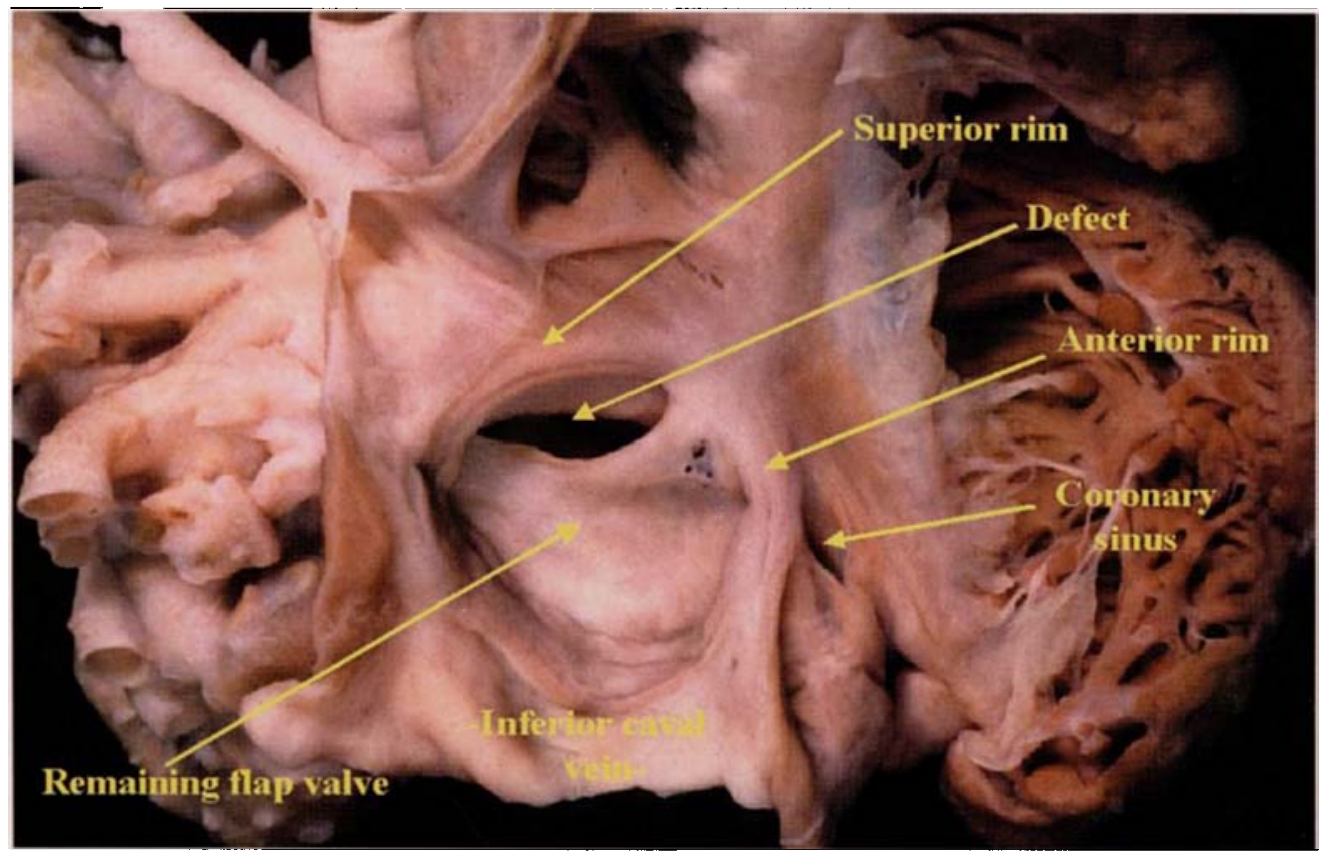

Figure 6.

This specimen shows a small elliptical defect between the upper margin of the deficient flap valve of the oval fossa and the infolded superior rim. This would be an ideal case for device closure.

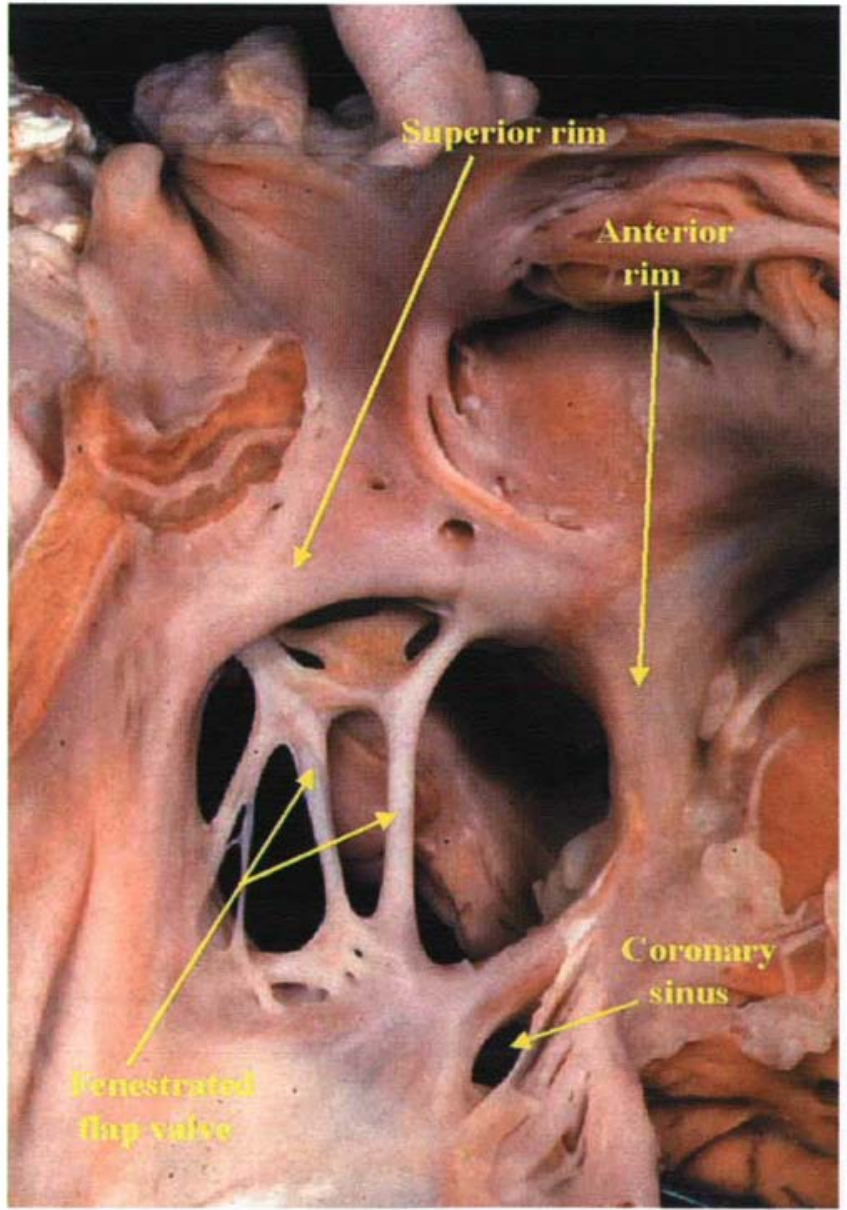

Figure 7.

The flap valve in this specimen is filigreed, producing multiple defects within the oval fossa. In effect, it is the margins of the oval fossa itself which form the boundaries of the defect. layer of extracardiac fibro-adipose tissue, also serves as a solid intracardiac buttress. When measuring in this area, therefore, dimensions can be judged relative to the hinges of the atrioventricular valves, which are usually off-set, with the tricuspid valve attached closer to the cardiac apex than the mitral valve. Inferiorly, it is important to measure the distance between the rim of the fossa and the mouth of the coronary sinus. This has been considered the shortest of the rims of the fossa, ${ }^{13}$ although anatomically the posterior area of the rim towards the mouth of the inferior caval vein is least infolded (Fig. 3). At any event, there is usually a substantial fold adjacent to the coronary sinus, and drainage of a persistent left superior caval vein to an enlarged sinus is not usually perceived as a contra-indication to interventional closure. As described, the posterior rim is the least well developed anatomically and, in addition, it is the hardest to image echocardiographically.,12 When assessing this rim, note should also be taken of the dimensions of the Eustachian valve, if present, since this can prove an impediment when inserting devices for closure. When traced superiorly, the posterior rim deepens markedly towards the termination of the right inferior pulmonary vein. The proximity of the defect to this venous structure is an important feature. In the normal heart, the superior rim of the defect, representing the area between the attachments of the superior caval vein and the pulmonary veins to the right and left atriums, respectively, is the best formed area of the circumference of the oval fossa (Fig. 5). In the presence of defects within the oval fossa, however, this superior margin of the rim is 
Figure 8.

In this specimen, the flap valve is virtually absent. Note that its remnant is attached anteriorly to the rim of the defect, which is oval since it represents the oval fossa.

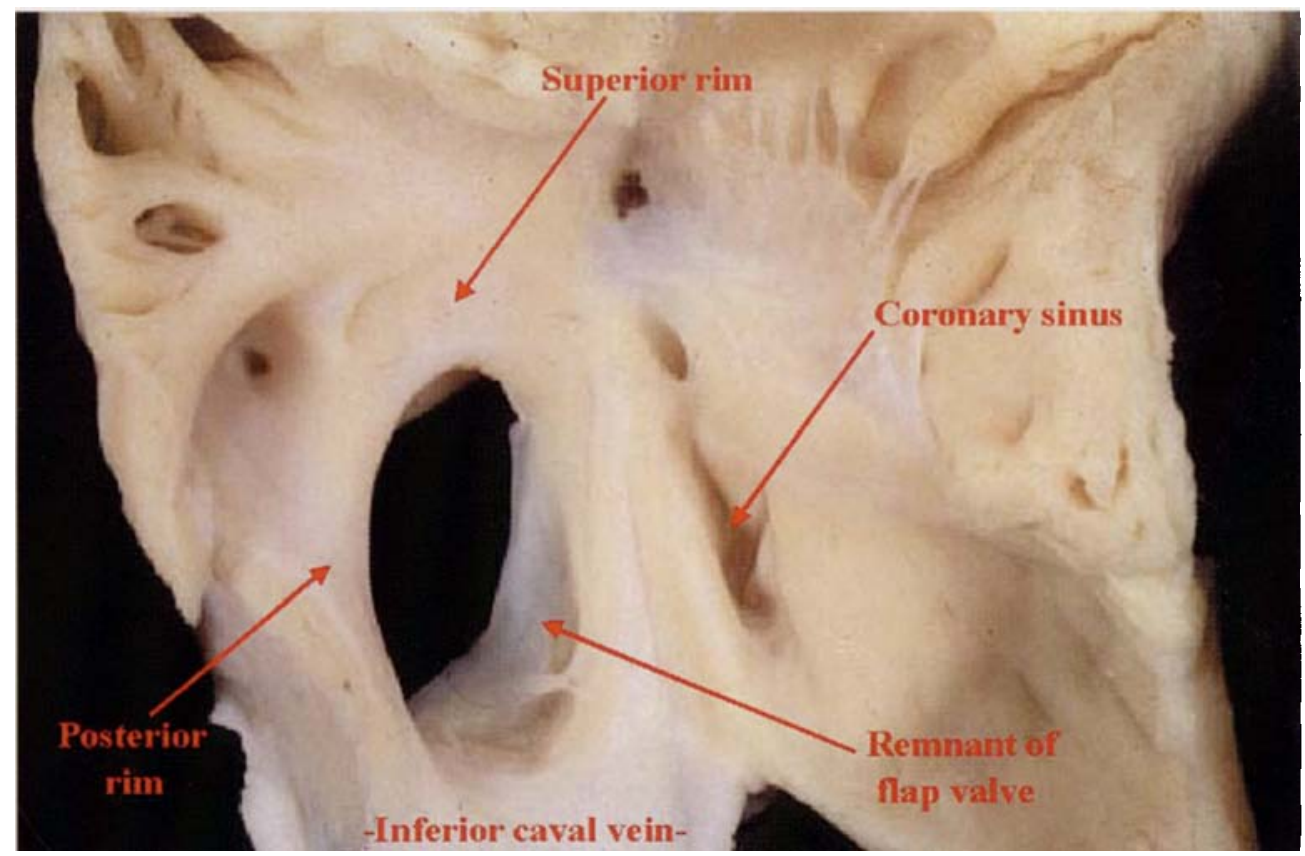

often effaced (Fig. 9), particularly in the setting of anomalous pulmonary venous connections. The extent of this part of the rim, nonetheless, is easily measured echocardiographically. ${ }^{12}$ When traced anteriorly, the infolded superior rim becomes continuous with the area of atrial wall adjacent to the aortic root (Fig. 3). This area is known as the "torus aorticus", or the aortic mound. It is a shallow infolding which does not provide much support for the rims or discs of the devices used for closure. It would be foolhardy to rely on this margin of the rim for secure closure. Small crevices are often to be found in the right atrial wall in this area which can give problems during echocardiographic examination. ${ }^{12}$

In terms of the location of the defect, always when the flap valve is deficient the interatrial communication itself is between the free border of the flap valve and the superior rim of the oval fossa (Fig. 6). In such cases with an extensive persisting flap valve, a significant part of the inferior wall of the fossa is the flap valve itself (Fig. 9). This structure is usually thin and fragile, and may be perforate, making it less than ideal for providing firm anchorage for a device in its own right. If this is considered a problem in the cathererisation laboratory, it would be prudent to consider the boundaries of the oval fossa itself as the margins of the defect, inserting a larger device than would be calculated on the basis of the extent of the flap valve, and inserting it lower in the oval fossa. As indicated, it may also be prudent to use a large device to block the entirety of the oval fossa when the flap valve is filigreed, although if two discrete openings are observed, it may well be feasible to insert two separate devices. Obviously when the flap valve is virtually or completely absent, then the area of the oval fossa is the area of the defect. The worry

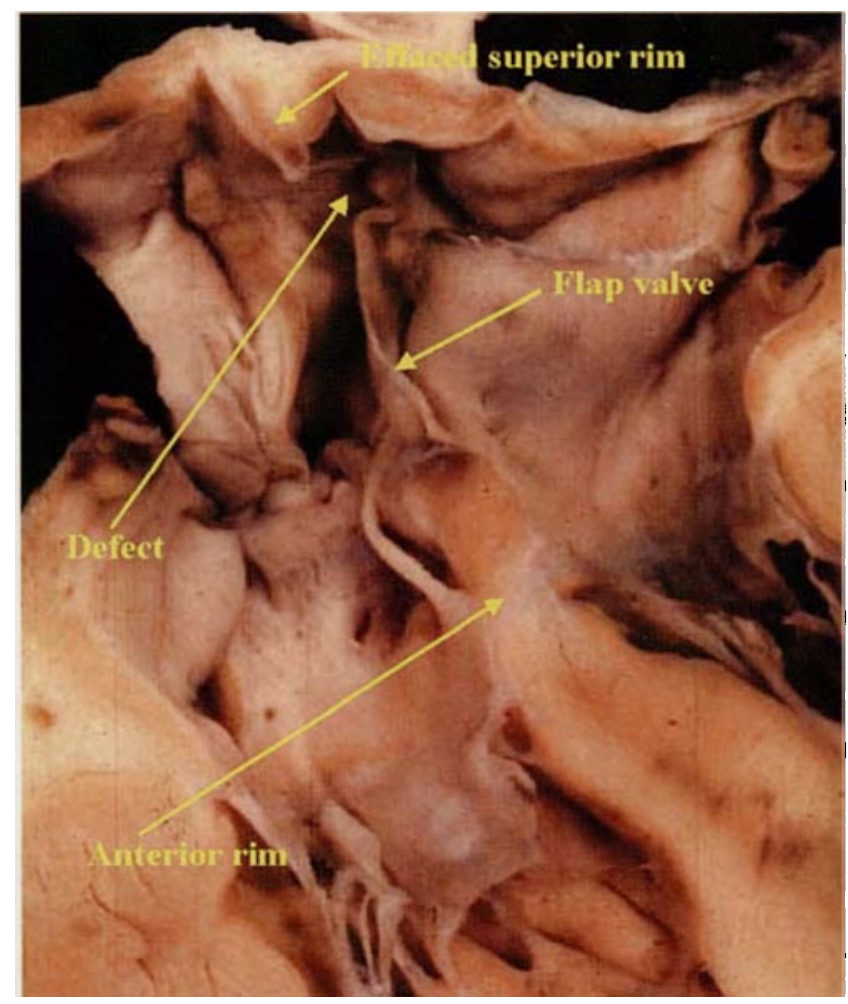

Figure 9.

This oblique cross section through the oval fossa shows bow the superior rim is effaced to large degree in the presence of a deficient flap valve, which is anchored anteriorly to the rim. 
in these circumstances is that the defect may be too big to permit safe closure. Even when the defect occupies the full extent of the fossa, however, the anatomic findings suggest that the margins of the defect are usually sufficiently secure to permit adequate anchoring of the device (Fig. 8). With regard to other adjacent atrial structures, the features of note, in decreasing order of importance, are the right pulmonary veins, the superior caval vein, the coronary sinus, the atrioventricular valves, and the inferior caval vein. In this respect, the location of the fossa itself can also vary markedly within the overall confines of the right atrium (compare Figs 10 and 11). It is, of course, a hazardous exercise to try to predict, on morphological grounds, those defects which can or cannot be closed. The proof of the pudding is always in the eating. For example, the size which would preclude closure depends on the dimensions of the patient versus the devices available for attempted closure. This will best be determined in the catheterisation laboratory. In the final analysis, therefore, it will be trial and error, coupled with experience, which will distinguish the defects which can and cannot safely be closed.

\section{The sinus venosus defects}

These poorly understood defects are difficult to diagnose. ${ }^{14}$ Accurate diagnosis, nonetheless, is important, since the anatomy dictates that, with presently available devices, they are unsuitable for interventional closure. This is because the holes are interatrial communications found outside the

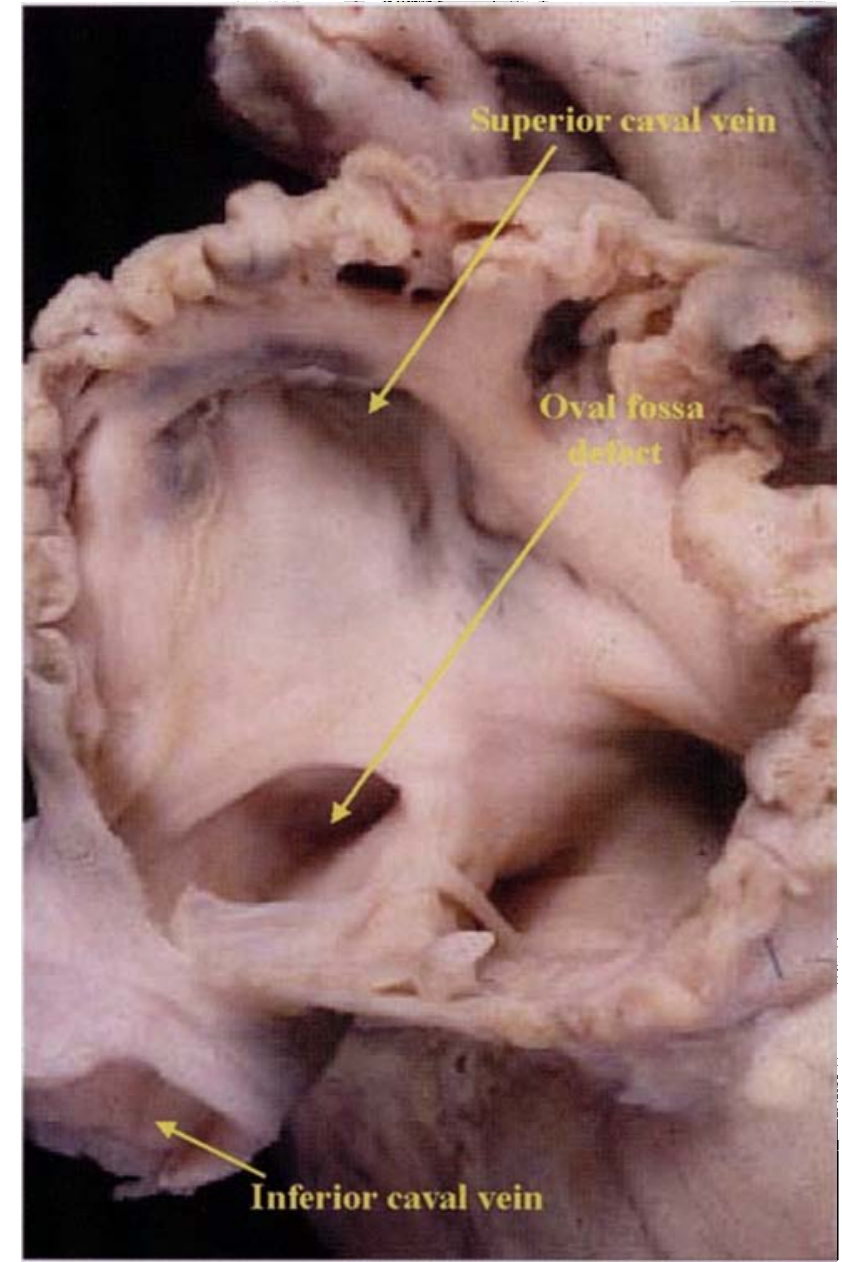

Figure 11.

In this beart, the oval fossa is adjacent to the mouth of the inferior caval vein - compare with Fig. 10.

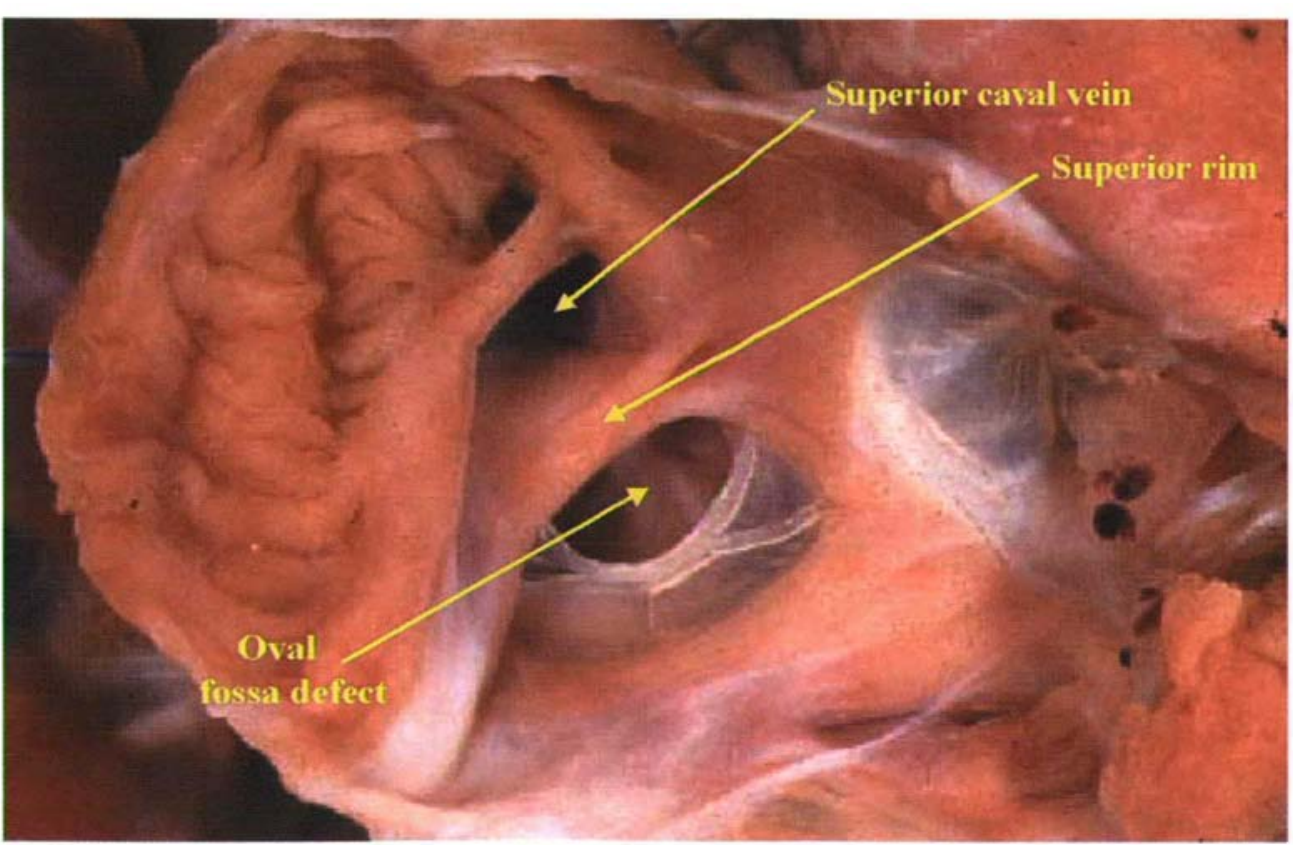

Figure 10.

In this specimen, the oval fossa is adjacent to the mouth of the superior caval vein. 
confines of the oval fossa. They are found in the mouth of usually the superior caval vein, and more rarely the inferior caval vein. ${ }^{15}$ In all the examples we have seen, there was associated anomalous connection of the right pulmonary veins. The key to diagnosis is that the mouth of the caval vein overrides the intact rim of the oval fossa (Fig. 12). The sinus venosus defect, therefore, can co-exist with a hole within the oval fossa. Indeed, it is not possible accurately to diagnose these defects unless it has been shown that the rims of the fossa themselves are intact. Because of the overriding, the walls of the caval vein are attached directly to both atriums, thus producing an interatrial communication. In autopsied hearts, it is possible to pass a probe through the intact superior rim of the oval fossa without entering the cardiac cavities (Fig. 13).

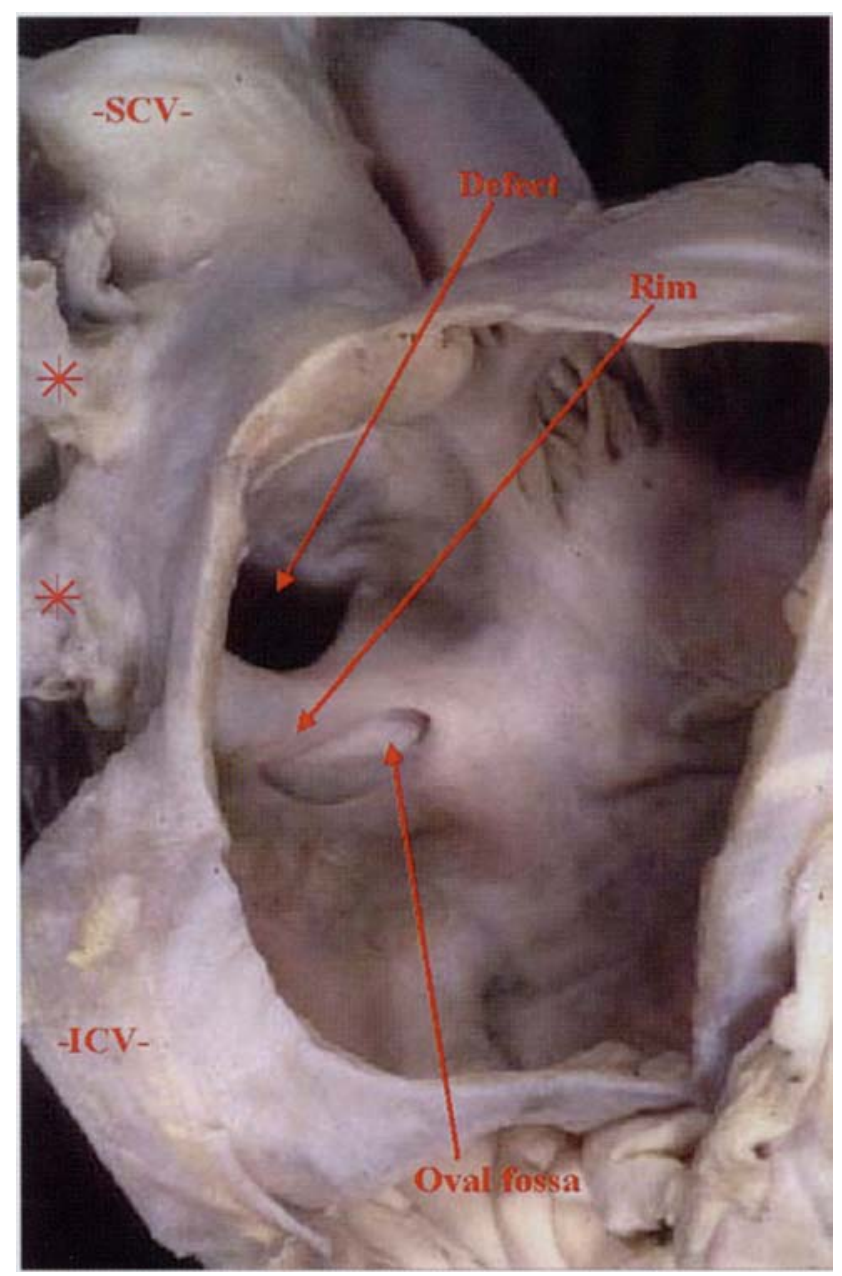

Figure 12.

This picture shows the nature of a sinus venosus defect. It is an interatrial communication outside the confines of the oval fossa, and in the mouth of the superior caval vein (SCV). Note the anomalous connections of the right pulmonary veins (starred).

\section{The coronary sinus defect}

This is the rarest type of interatrial communication, and is usually found with anomalous connection of a left superior caval vein to the roof of the left atrium. It exists because of "unroofing" of the normal course of a persistent left superior caval vein into the left atrioventricular groove, and thence to the mouth of the coronary sinus (Fig. 14). The right atrial orifice of the coronary sinus, in consequence, functions as an interatrial communication (Fig. 15). It can also be found, even more rarely, when there is absence of a patent left superior caval vein. The anatomy suggests that, if properly diagnosed, it should be possible to close such holes non-surgically with a suitable device. In most instances, however, the defects are part of a more complex malformation, so opportunities for non-surgical closure will be rare.

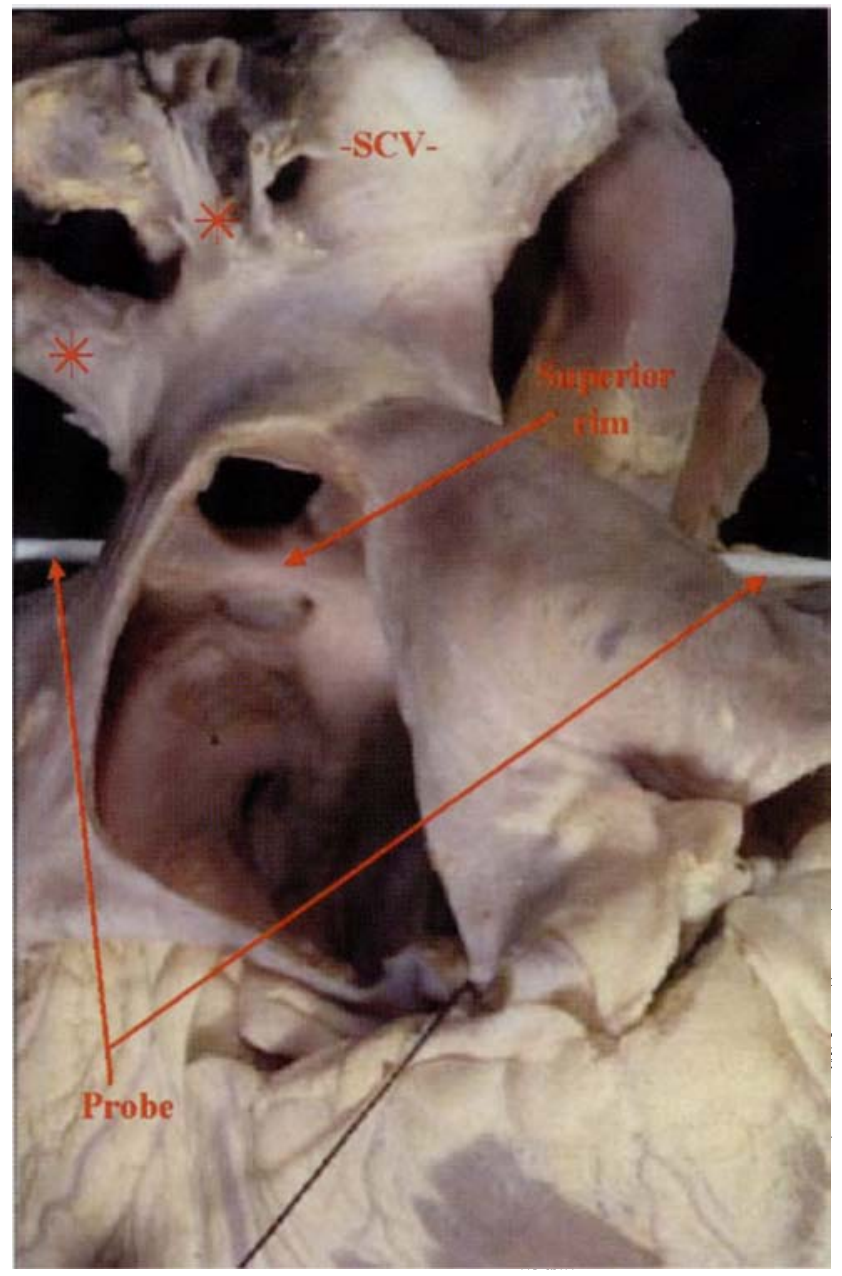

Figure 13.

In the beart with a sinus venosus defect shown in Fig. 12, it was possible to pass a probe through the fibroadipose core of the rim of the oval fossa, the rim itself forming the floor of the interatrial communication. Abbreviations as for Fig 12 . 


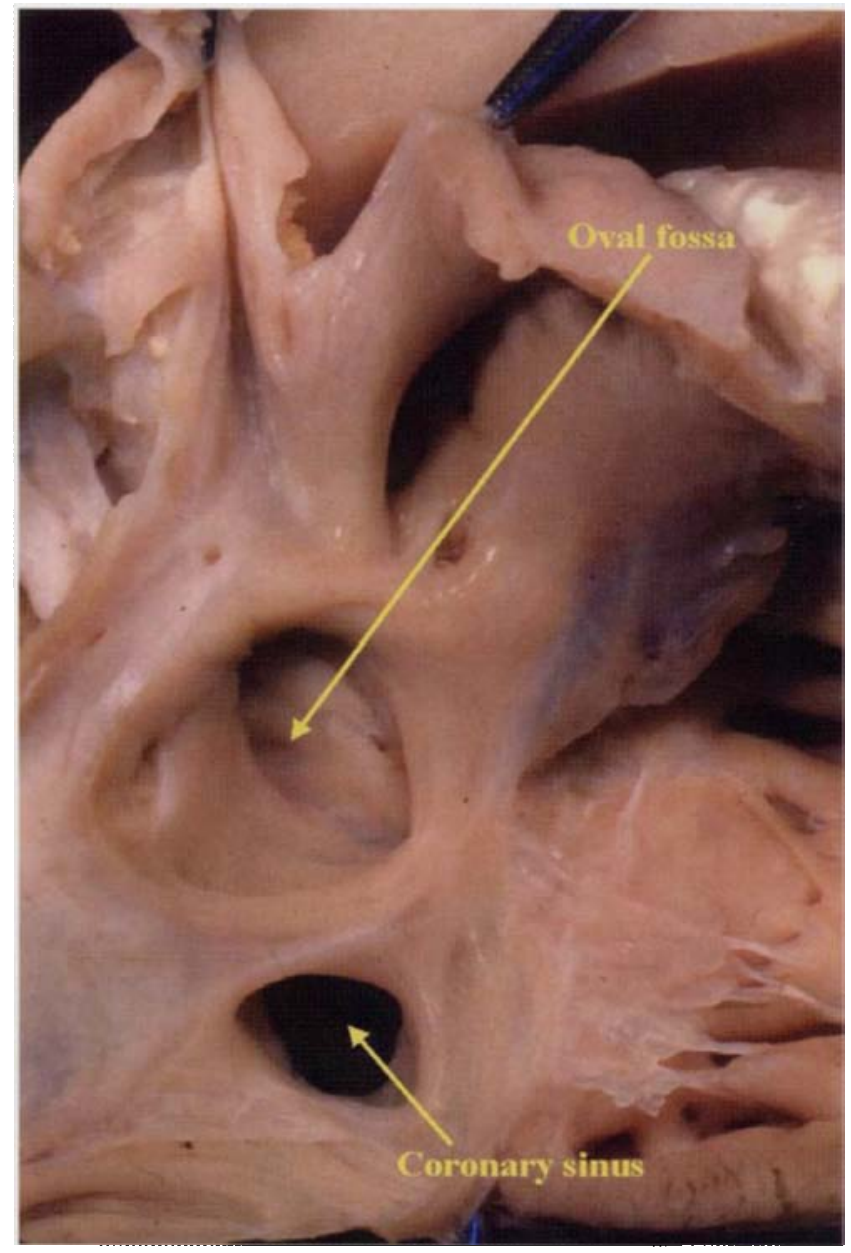

Figure 14.

The right atrium has been opened to show the enlarged mouth of the coronary sinus, wbich is functioning as an interatrial communication (see Fig. 15).

\section{The "Ostium Primum" defect}

This defect is also a communication between the atrial chambers outside the confines of the oval fossa, this time because of atrioventricular septal deficiency in the setting of a common atrioventricular junction (Fig. 16). The heart has all the stigmas of atrioventricular septal defects, and the characteristic feature is binding down of the bridging leaflets to the crest of the ventricular septum so that there is no potential for interventricular shunting. ${ }^{16,17}$ Almost always the bridging leaflets are also joined to each other so that the common atrioventricular junction is guarded by separate right and left atrioventricular valves. The left valve, because of the common atrioventricular junction, has the typical trifoliate configuration of an atrioventricular septal defect. Because the inferior margin of these defects is formed by the bridging leaflets attached to the ventricular septum, it is

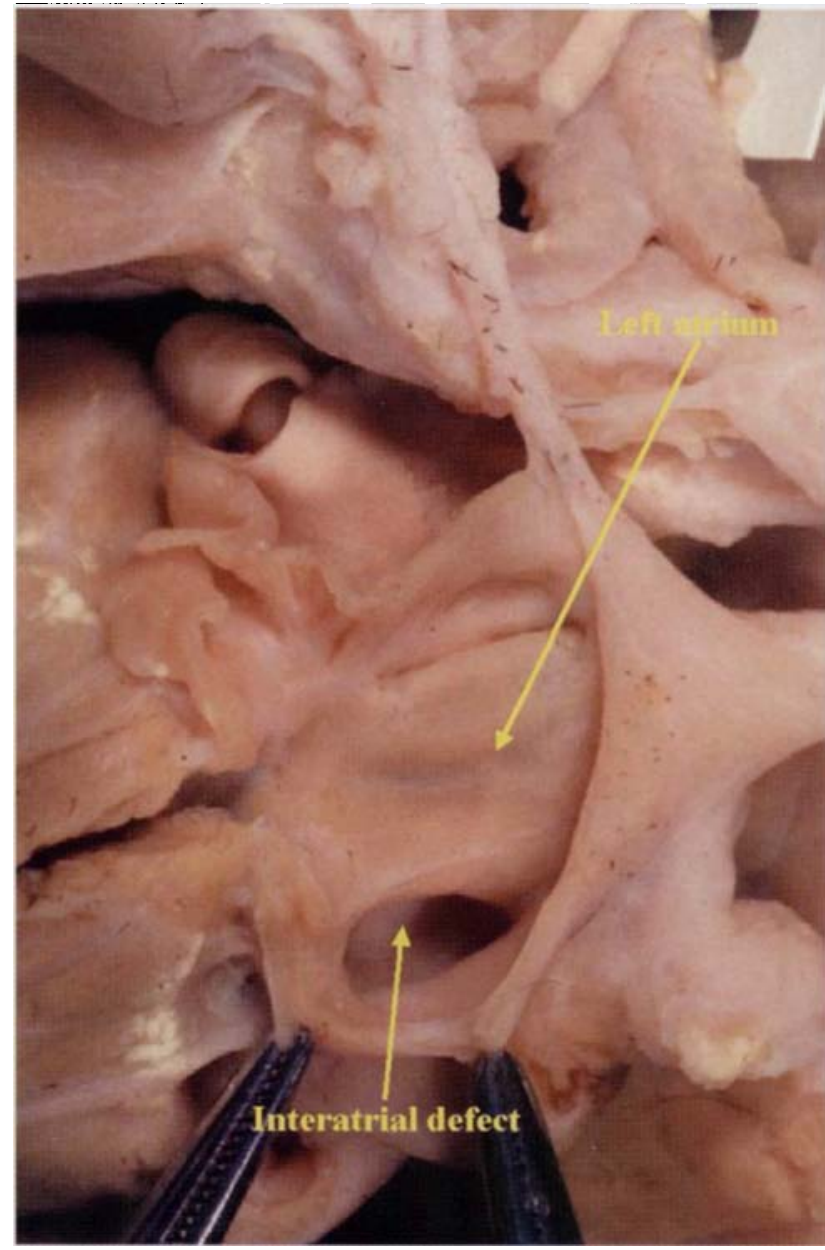

Figure 15.

The left atrial view of the beart shown in Fig. 14 reveals that the coronary sinus acts as an interatrial communication because of complete absence of the walls which usually separate the sinus from the cavity of the left atrium.

difficult to see how the hole between the atriums could be closed by insertion of a device without the device distorting the pattern of closure of the left atrioventricular valve. Because the integrity of the left valve is known to be the major determinant of the success of surgical treatment, it seems unlikely that non-surgical closure will be attempted for treatment of the "ostium primum" defect, albeit that the arrangement of the hole itself would not rule out such closure.

\section{Conclusion}

The success of non-surgical closure of holes between the atriums is critically dependent on proper selection of patients, and also selection of the most appropriate device. The key to this is an appreciation of the structure of the oval fossa and its relationships to adjacent atrial structures, and the 


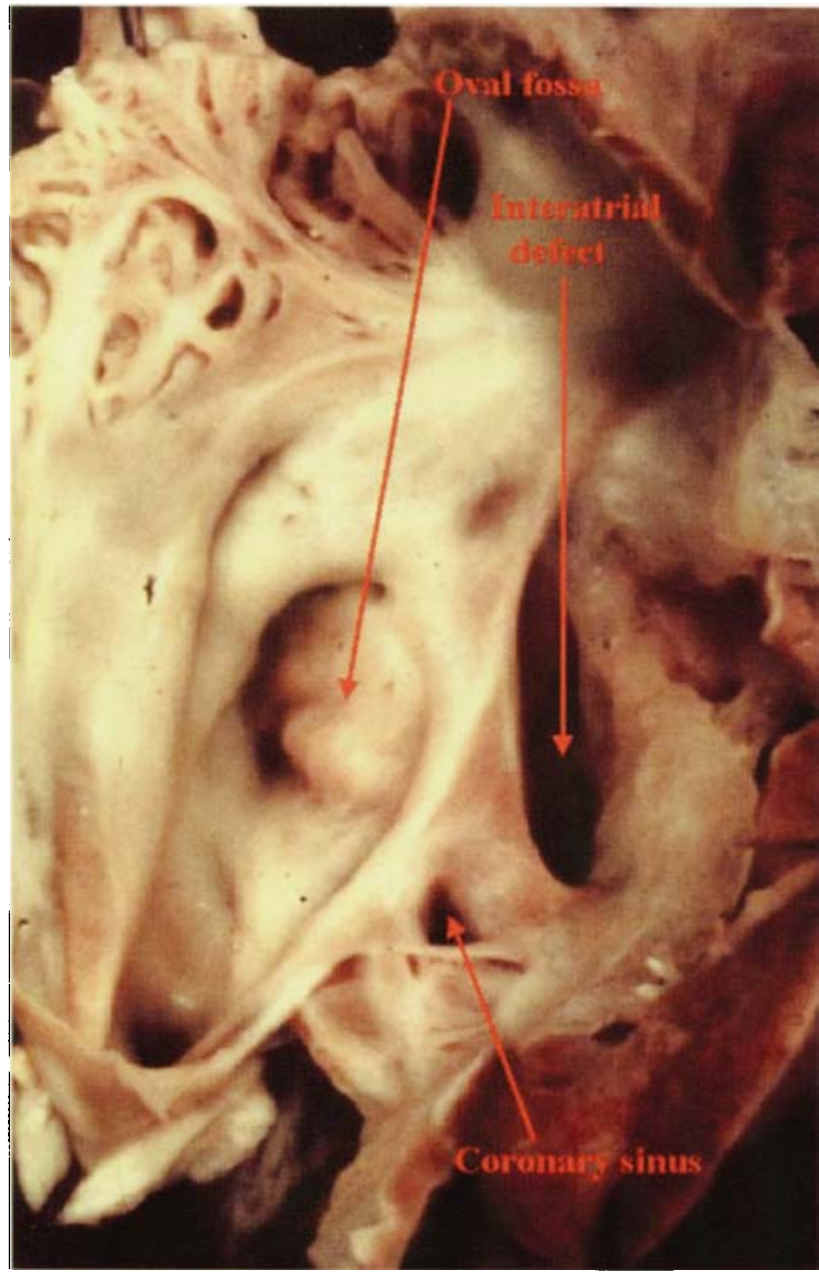

Figure 16.

This shows the essence of the "ostium primum" defect. Note that the atrial septum itself is well-formed, with an intact oval fossa. The interatrial communication is an atrioventricular septal defect permitting only interatrial shunting in the presence of a common atrioventricular junction.

recognition that the more complex interatrial communications are found outwith the confines of this fossa. With increasing experience, and the everincreasing improvements of the devices currently available for closure, it seems that more and more defects found within the oval fossa will prove suitable for a non-surgical approach. Of the other interatrial communications, only the structure of the coronary sinus defect seems to lend itself to the potential for non-surgical closure. Isolated defects of this kind, nonetheless, are exceedingly rare.

\section{Acknowledgement}

Professor Anderson is supported by generous grants from the British Heart Foundation in association with the Joseph Levy Foundation.

\section{References}

1. Lock JE, Rome JJ, Davis R, Van Praagh S, Perry SB, Van Praagh $R$, Keane JF. Transcatheter closure of atrial septal defects. Experimental studies. Circulation 1989;79: 1091-1099.

2. Ferreira SMAG, Ho SY, Anderson RH. Morphologic study of defects of the atrial septum within the oval fossa: application for transcatheter closure of left-to-right shunt. Br Hearr J 1992;67: 316-320.

3. Chan KC, Godman MJ. Morphological variations of fossa ovalis atrial septal defects (secundum): feasibility for transcutaneous closure with the clam-shell device. Br Heart J 1993;69: 52-55.

4. Bemurat L, Jimenez $M$, Roudaut $R$, Laborde $N$, Roques $X$ Grimaud JP, Choussat A. Surgical evaluation of transthoracic tridimensional echocardiography in the anatomic study of atrial septal defect. Arch Mal Coeur Vaiss 1999;92: 573-580.

5. Anderson RH, Brown NA. The anatomy of the heart revisited. Anat Rec 1996; 246: 1-7

6. Cosio FC, Anderson RH, Kuck K, Becker A, Borggrefe M Campbell RWF, Gaita F, Haïssaguerre $M$, RufilanchasJJ Thiene G, Wellens HJJ, Langberg J, Benditt DG, Bharati S, Klein G, Marchlinski F, Saksena S. Living anatomy of the atrioventricular junctions. A guide to electrophysiological mapping. A consensus statement from the Cardiac Nomenclature Study Group, Working Group of Arrhythmias, European Sociery of Cardiology, and the Task Force on Cardiac Nomenclature from NASPE. Circulation 1999;100: e31-e37; Eur Heart J 1999;20: 1068-1075; J Cardiovasc Electrophysiol $1999 ; 10 ; 1162-1170$.

7. Anderson RH, Webb S, Brown NA 1999 Clinical anatomy of the atrial septum with reference to its developmental components. Clin Anat 1999;12: 362-374.

8. Chauvin M, Shah DC, Haissaguerre M, Marcellin L, Brechenmacher $\mathrm{C}$. The anatomic basis of connections between the coronary sinus musculature and the left atrium in humans. Circulation 2000;101: 645-656.

9." Hagen PT, Scholz DG, Edwards WD. Incidence and size of patent foramen ovale during the first 10 decades of life: an autopsy study of 965 normal hearts. Proc Staff Meet Mayo Clin 1984;59: 1489-1494.

10. Fukazawa M, Fukushige J, Veda K. Atrial septal defects in neonates with reference to spontaneous closure. Am Heart $\mathbf{J}$ 1988;116: 123-127.

11. Chan KC, Godman MJ, Walsh K, Wilson N, Redington A, Gibbs JL Transcatheter closure of atrial septal defect and interatrial communications with a new self expanding nitinol double disc device (Amplatzer septal occluder): multicentric UK experience. Heart 1999;82: 300-306.

12. Elzenga $\mathrm{NJ}$. The role of echocardiography in transcatheter closure of atrial septal defects. Cardiol Young 2000;10... (this issue)

13. Lock JE, Cockerham JT, Keane JF, Wakely PE, Fellows KE Transcatheter umbrella closure of congenital heart defects. Circulation 1987;75: 593-599.

14. Al Zaghal AM, Li J, Anderson RH, Lincoln C, Shore D, Rigby ML. Anatomical criteria for the diagnosis of sinus venosus defects. Heart 1997;78: 298-304.

15. Ettedgui JA, Siewers RD, Zuberbuhler JR, Anderson RH Echocardiographic diagnosis of inferior sinus venosus defects. Cardiol Young 1992; 2: 338-341.

16. Anderson RH, Baker EJ, Ho SY, Rigby ML, Ebels T. The morphology and diagnosis of atrioventricular septal defects. Cardiol Young 1991; 1: 290-305.

17. Falcao S, Daliento L, Ho SY, Rigby M L, Anderson R H. Cross sectional echocardiographic assessment of the extent of the atrial septum relative to the atrioventricular junction in atrioventricular septal defect. Heart 1999;81: 199-205. 